\title{
TERMITE-TERMITE INTERACTIONS: WORKERS AS AN AGONISTIC CASTE*
}

\author{
BY BARBARA L. THORNE \\ Museum of Comparative Zoology \\ Harvard University \\ Cambridge, Massachusetts 02138
}

Termite soldiers are a defensive caste. Their heavily sclerotized head capsules can be equipped with hard mandibles capable of crushing, pinching, piercing, or slashing predators. Soldier castes of many phylogenetically advanced species have well-developed frontal glands and are capable of exuding or spraying chemical secretions. Such chemical armaments are toxic, irritable, or oily fluids which can impair physiological, sensory and/or mechanical faculties of the recipient (Prestwich, 1979). Termite soldiers are thus formidable opponents for ants and vertebrate predators. Soldiers are fed by workers and their behavior within the colony is generally limited to signaling alarm, participating in defense, and organizing foraging expeditions (Stuart, 1969; Traniello, 1981).

Despite their specialization, however, soldiers are not the only defensive caste in a termite colony: worker termites of some species (from four families) are known to be able fighters in termite-termite aggressive interactions [Kalotermitidae (Grassi and Sandias, 18961897; Dropkin, 1946); Hodotermitidae (Nel, 1968); Rhinotermitidae (Pickens, 1934; Clément, 1978); Termitidae (Dudley and Beaumont, 1889a,b; Andrews 1911)]. This paper explores intra- and interspecific agonistic encounters among termites, and focuses on the roles of workers and soldiers in such conflicts.

The report is presented in two sections, corresponding to two sets of experiments on this topic. Section A describes a field manipulation inducing intraspecific encounters among colonies of Nasutitermes corniger in Costa Rica. Section B presents data on laboratory experiments examining intra- and interspecific interactions among four species of Panamanian termites.

*Manuscript received by' the editor February 1, 1982 


\section{A. INTRASPECIFIC FIELD EXPERIMENT: NASUTITERMES CORNIGER}

Nasutitermes corniger (Motschulsky) is a common arboreal termite ranging through much of Central and northern South America (Thorne, 1980). Large carton nests contain up to 800,000 termites (Thorne and Noirot, 1982) and, with the addition of foragers, total colony size may exceed a million individuals. Distinct foraging trails, covered by carton galleries, are visible issuing from a nest and proceeding along tree branches, trunks, and the ground surface. The termites also travel underground and in galleries located within trees or fallen logs. $N$. corniger foraging trails can radiate many meters from the parent colony.

Given the density of $N$. corniger colonies in primary forest (7.0 \pm 1.8 per hectare in the Hubbell Plot of Barro Colorado Island, Panama, $N=4$ hectares) and in areas of young second growth (27 in one hectare in Frijoles, Panama) (Thorne, unpub. data), it is likely that, at least occasionally, foraging parties from different colonies encounter one another in the midst of exploring or exploiting a local food source. Observation of a natural inter-colony encounter would be difficult. It would require tracking single foraging trails, which would undoubtedly result in disturbance as one cleared away the forest litter to locate foragers. Even if trails could be accurately followed without disruption, it would be rare to view simultaneous interception with an active trail known to be from a second colony. Because the odds of witnessing such a natural event are low, I forced an encounter through a transplant experiment.

\section{METHODS}

On the morning of 18 August, 1978 three Nasutitermes corniger nests were collected from separate areas of second growth near Sirena headquarters of Corcovado National Park, Osa Peninsula, Costa Rica. The nests measured 29.8, 52.7, and $41.9 \mathrm{~cm}$ in height and $26.0,29.8$, and $26.0 \mathrm{~cm}$ in diameter, respectively. Nests were sawed from their host trees and hand-carried to the experimental site. Each colony was suspended on a wire from one of two branches of a large tree (Fig. 1). The nests were hung in an equilateral triangle such that the distance from their base to the ground was $60 \mathrm{~cm}$, the distance from the edge of each colony to each neighbor was $50 \mathrm{~cm}$, and the original compass orientation of each colony was main- 


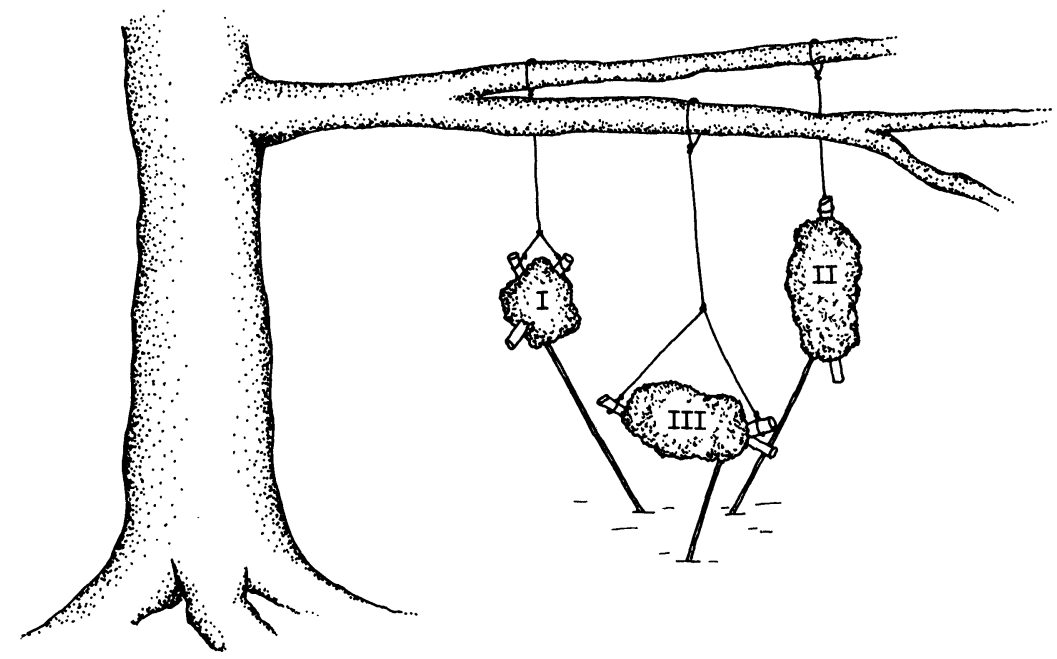

Figure 1. Field set-up for intraspecific encounter experiment involving Costa Rican Nasutitermes corniger.

tained. A coat of tanglefoot was placed at the base of each wire strand (near the point of attachment to nest support branches) to prevent termites from crawling up the wires. A $3.5 \times 3.5 \mathrm{~m}^{2}$ plot beneath the nest triangle was completely cleared of leaf litter, forest debris and herbaceous plants so that movement patterns of the termite trails could be monitored. At 7:30 p.m. that evening stick "ramps" $(90 \mathrm{~cm}$ in length, $1 \mathrm{~cm}$ in diameter) were installed to connect the nests to the ground. The tips of the sticks were shallowly inserted into both the nest carton and ground surface for support. Bases of the ramps also ended in vertices of an equilateral triangle on the ground, $20 \mathrm{~cm}$ from tip to tip.

\section{RESULTS}

Hanging above the ground from a single strand of wire, each nest was an island in mid-air: no escape routes were open for the termites. By dusk of the day of collection, soldiers and workers from all colonies were crawling over the peripheries of their nests. This activity gained participants and momentum: at 7:30 p.m. each nest was a seething mass of termites. The stick ramps were embedded to 
connect the nests to the ground. Immediately following implantation termites swarmed onto the ramps, soldiers in the lead followed by a mixture of soldiers and workers. Only four white immatures were seen leaving the nests throughout the experimental period.

As they reached the ground groups fanned out: termites from a single colony divided into several ribbons heading in different directions. Because of the close proximity of the ramp exits, it was inevitable that encounters occur between trails from different colonies. The meetings were not passive. Soldiers oriented towards (and apparently squirted) termites from other colonies, but this did not seem much of a deterrent to recipients. The major defense stemmed not from the soldiers, but from the Nasutitermes workers.

Workers from different colonies grabbed each other with their mandibles and locked in one-on-one conflict. Pairs of workers squirmed and bent with vigor, often until the death of both. Occasionally a third or fourth worker would join the engagement, but usually only temporarily. Workers avidly attacked soldiers as well, grabbing at the legs and occasionally biting the abdomen.

The next morning worker carcasses littered the arena over an area of approximately $1,500 \mathrm{~cm}^{2}$, with some battle "patches" as far as $1.5 \mathrm{~m}$ from the center of the ramp triangle. The density of bodies was often quite high ( $25-50$ dead in a $4.0 \mathrm{~cm}^{2}$ area). Surviving termites did not appear to cannibalize the dead. Ants, flies, staphylinid beetles, and wasps began scavenging the termite carcasses.

How were foraging trail routes influenced by the intersection battles? Agonistic confrontations were instigated when at least one colony was in the process of establishing or changing a foraging route, i.e. in a scouting phase. Preliminary observations (Fig. 2) suggest that both colonies' foraging pathways were displaced by encounters - trails were repulsed from the meeting site following battles lasting 10-30 minutes. One colony may maintain a trail tangential to the "battle field", but I did not see one continuing through an area of dead termites.

It is difficult to determine the effect of agonistic encounters on final foraging path location. In isolation a colony establishes foraging routes by scouting in a broad network, but several hours later this highly branched fan collapses into a single actively travelled ribbon with few side trails. Thus the fact that termites have traversed a given area in no way assures that route as the path of a final 

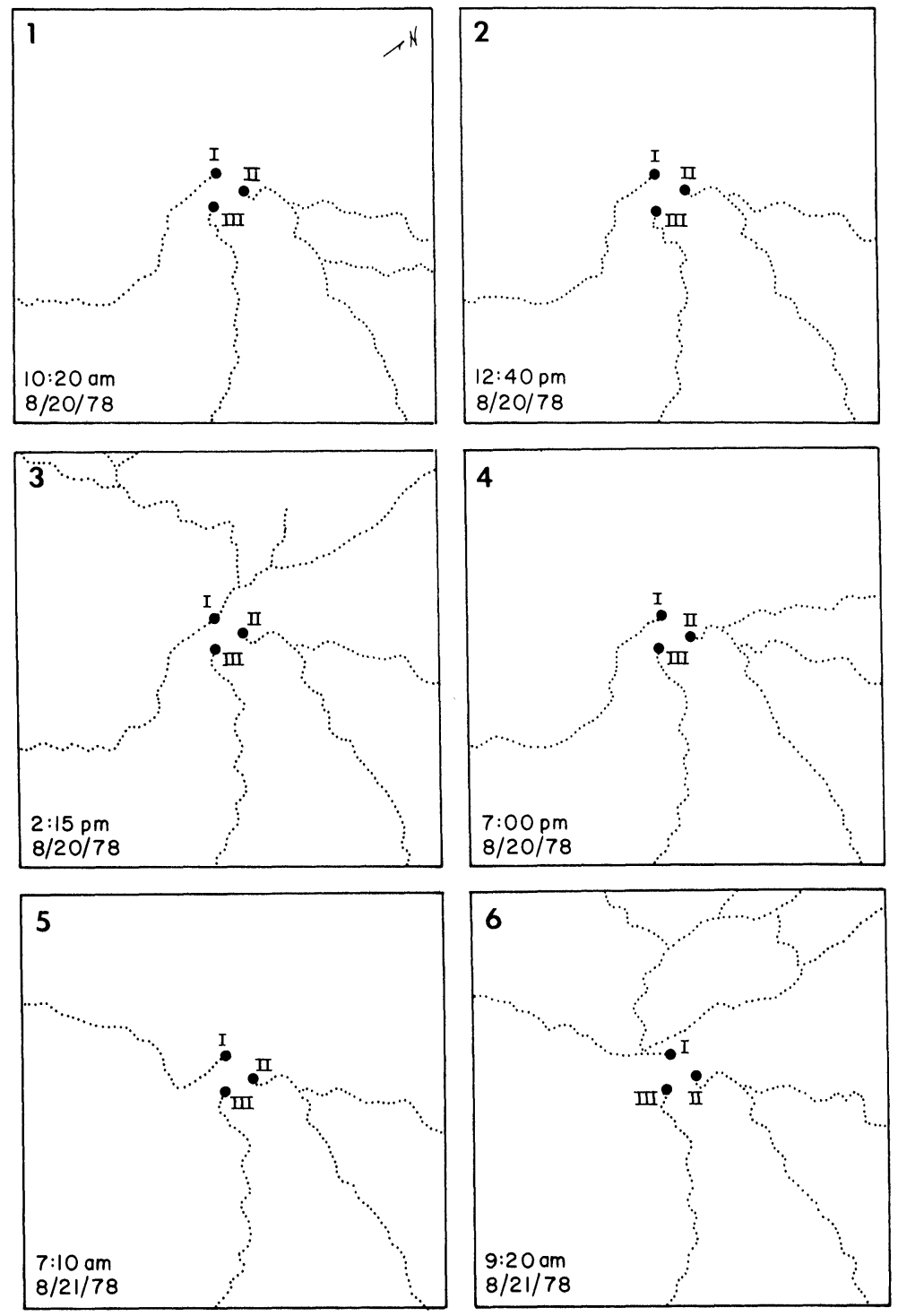

Figure 2. Periodic maps of ground foraging trails departing from the tips of exit ramps attached to suspended Nasutitermes corniger colonies (Section A). Central dots indicate positions of the ramps. Maps are $3.5 \times 3.5 \mathrm{~m}^{2}$. 
foraging trail. Battles may be a deterrent to formation of a given path, but their influence is difficult to assess independently.

Foraging path trajectories from the three nests were monitored for two and one half days following initiation of the experiment (see Fig. 2 for the final 24 hour period). Once a scouting fan condensed into a single pathway the positions were relatively stable. Minor adjustments in path locations did occur periodically, and activity on specific trails varied from day to day and even hour to hour. Occasionally (usually in the evening) new scouting parties would emanate from the ramp tip or as a tributary of the main trail network.

Construction of trail covers varied from colony to colony. Colony III began covering both its ramp and ground trails quickly (a total of $64 \mathrm{~cm}$ of trail covered by $7 \mathrm{am}, 20$ August). In contrast, Colonies I and II had only $19 \mathrm{~cm}$ and $3.2 \mathrm{~cm}$ of covering, respectively, at $7 \mathrm{a} . \mathrm{m}$. on 20 August. These same relative speeds were repeated when the initial experiment was replicated from 21 to 22 August. Building behavior also showed distinct inter-colony variation, mainly in the amount of advance siding deposited before the trails were roofed.

To replicate the first nights' encounters, I removed the three ramps and scraped clean the entire $3.5 \times 3.5 \mathrm{~m}^{2}$ grid at noon on 21 August. This caused attrition of those individuals on the ground and out foraging, but the established trails had to be destroyed to induce active scouting. New ramps $(90 \mathrm{~cm}$ long) were installed at $6: 30$ p.m., with ends touching the ground in an equilateral triangle of side length $25 \mathrm{~cm}$.

Members of Colony I came down their ramp fairly rapidly and began three major paths from its tip, one to the southeast, one to the north, and one due west. At 7 p.m. termites from Colony II began coming down their ramp and immediately began to fight with Colony I's southeast-bound foragers. When the first workers from Colony III came down their ramp and encountered foreigners, they rapidly reversed direction and returned en masse to the mouth of their nest, after which a large group of Colony III termites stormed down the ramp. The possibility of worker recruitment in these circumstances should be investigated. The battle between Colonies I and III was vehement for 20 minutes; after 30 minutes Colony I's southeast trail was abandoned. Colony III established a new trail $180^{\circ}$ away from the direction of original interference with Colony I. 


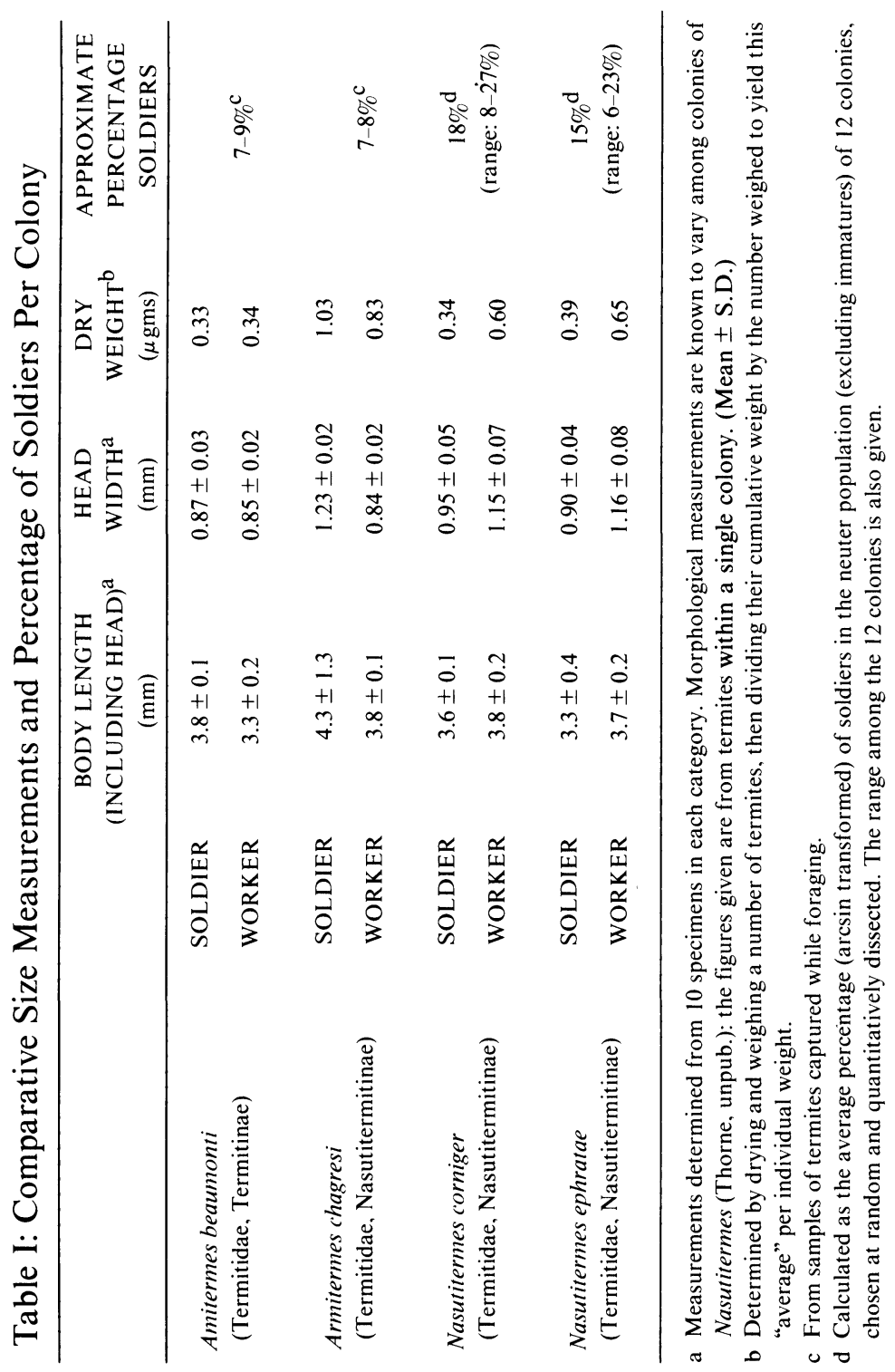


In these and several other encounters that night, aggressive interactions among colonies were similar to those described earlier.

\section{B. INTRA- AND INTERSPECIFIC LABORATORY EXPERIMENTS: Termite-Termite InTERACTIONS AMONG Four Panamanian Species}

To examine conflicts among colonies and species of sympatric termites I staged laboratory encounters in pairwise tests: soldiers vs soldiers, soldiers vs workers, and workers vs workers. Characteristics of the four species used in these experiments are summarized in Table I. Amitermes beaumonti soldiers have curved mandibles; Armitermes chagresi soldiers have long, curved mandibles and a prolonged nasus; and soldiers of Nasutitermes corniger and $N$. ephratae are nasutoid with vestigal mandibles (Fig. 3).

\section{METHODS}

Experimental trials were conducted in March and April, 1981 in the Smithsonian Tropical Research Institute laboratory on Barro Colorado Island (BCI), Panama ( $9^{\circ} 09^{\prime} \mathrm{N}, 79^{\circ} 51^{\prime} \mathrm{W}$ ). All Amitermes beaumonti and Armitermes chagresi were collected from nests on BCI; samples of Nasutitermes corniger and N. ephratae were from colonies in Frijoles, Panama ( $4 \mathrm{~km}$ east of BCI). Pairwise encounters were staged in petri dish arenas $(4.6 \mathrm{~cm}$ diameter) lined with moist filter paper. Equal numbers of termites, soldiers or workers, from each colony were introduced to an arena simultaneously. Dishes were then covered and left undisturbed in darkness for 12 hours. After the interaction period survivors were counted: conspicuously injured individuals were considered as dead. Most worker-worker trials involved 50 individuals from each colony (only large workers (ㅇ) were used from Nasutitermes colonies; Amitermes and Armitermes have monomorphic worker castes). When soldiers of Amitermes or Armitermes were involved in a trial, and in occasional trials involving Amitermes or Armitermes workers, fewer individuals were available so experiments proceeded with less than 50 termites from each colony. In Table II the number of individuals from each colony used in each trial is indicated in parentheses following the survival percentages. A minimum of three trials were conducted for each intra- and interspecific interaction. Each such 

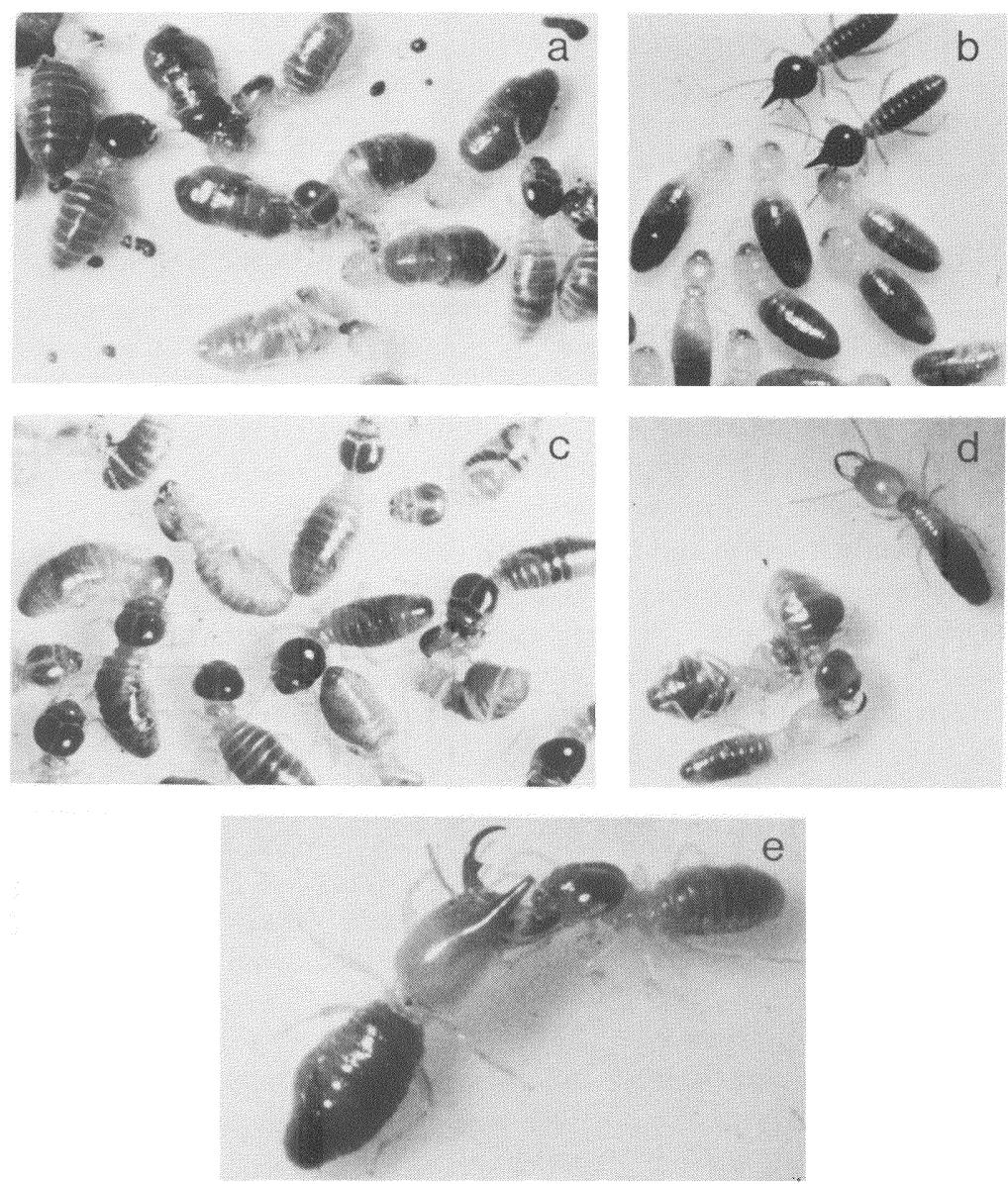

Figure 3. Termite-termite interactions (Section B). a. Nasutitermes corniger workers (dark heads) vs Armitermes chagresi soldiers (light heads). b. N. corniger soldiers vs Amitermes foreli workers. c. $N$. corniger intraspecific worker-worker encounter. d. Amitermes foreli soldier vs $N$. ephratae worker. e. Armitermes chagresi soldier vs $N$. ephratae worker. 
trial pitted termites from different colonies. After the 12 hour encounter all dead termites from selected trials were collected and examined for injuries under a dissecting microscope.

\section{RESULTS}

Survival percentages of termites involved in each trial are presented in Table II. For conspecific interactions among members of a single caste (soldier vs soldier or worker vs worker), it was not possible to differentiate colony affiliation so a single survival percentage is indicated. These figures indicate whether or not a fight ensued, although it is impossible to determine if one colony suffered more or less mortality than the other.

Variability within and between blocks of Table II is high. Among some replicates mortality is low for both groups of interacting termites (signified by a '-' at the base of the block). Some encounters suggest consistent "victors", represented by an arrow pointing in the direction of that party. Other groups of interactions indicate agonistic behavior on both sides ('+'), without clear assignment of a "winner" or "loser".

All interspecific worker-worker encounters resulted in a fight, often with a trend suggesting a "dominant" species but with sufficient variation among trials to prevent assigning a "winner". Such variation may result from relative differences in individual colony nutrition, age, health, and history. For example, an interaction between two strong colonies may be quite different from a similar encounter between members of a weak and a strong colony. It should be noted that soldiers are absent during worker-worker trials, which may affect the excitability and response of workers.

Intraspecific worker-worker engagements demonstrated variable aggression within Nasutitermes corniger and N. ephratae, and no lethal attacks in any of the Amitermes or Armitermes trials. Fighting among conspecific Nasutitermes colonies is variable and apparently influenced by as yet uninvestigated factors. In these experimental trials, aggressive interactions generally occurred, although in all but one $N$. corniger trial well over half of the workers survived the 12 hour meeting. I have previously observed both extremes in conspecific Nasutitermes corniger encounters: $100 \%$ mortality and $100 \%$ survival, even among colonies from distant locations. Dudley $\&$ Beaumont $(1889 \mathrm{a}, \mathrm{b})$ report that mixing two $N$. corniger colonies 
resulted in lethal fights. Variance in response may be due to experimental protocol, particularly isolation of a colony's soldiers and workers. Under natural conditions a colony's soldiers and workers may interact with one another in recognition of and response to foreign termites. The soldier secretion has been demonstrated an alarm pheromone in N. exitiosus, although workers showed little reaction to fresh secretion presented on an applicator (Eisner et al. 1976).

In these experiments soldiers and workers from different $N$. corniger or Armitermes chagresi colonies did not fight, while soldierworker conflict did occur in N. ephratae and Amitermes beaumonti conspecific encounters. In the field manipulaton involving Costa Rican $N$. corniger (Section A), soldier-worker battles were observed.

Summarizing other general trends, $N$. ephratae workers scored relatively well in worker-worker inter-specific encounters, although they were not consistent victors over Armitermes workers. Both Amitermes and Armitermes soldiers faired relatively well in most encounters while Nasutitermes soldiers were less successful. In intraspecific Armitermes chagresi interactions, only soldier-soldier conflict was observed; among Amitermes beaumonti, only meetings between soldiers and workers stirred fighting. Such patterns imply species differences in communication, meaning, and recognition of any colony-specific odors.

Injuries suffered by the dead during the interaction experiments were scored for several trials, and are summarized in Table III. Presence or absence of damage to the abdomen was scored, though no analysis of extent of abdominal injury was recorded because the exact number of wounds or punctures was difficult to assess. The percentage of dead with abdominal wounds is generally high.

Table II (Following pages): Survival Percentages of Panamanian Termites in Paired Laboratory Encounters

Paired encounters were staged matching equal numbers of termites (number of individuals from each colony given in parentheses following trial results). The total percentage of individuals surviving the 12 hour meeting is given for intraspecific soldier-soldier and worker-worker interactions: inability to identify colony affiliation prevented comparative percentages. All other trials report the survival percentage of the termites listed to the left over that of termites listed on top. Arrows at the base of a block point in the direction of a consistent "winner": arrows in parentheses note a less pronounced tendency, '-' indicates few deaths on either side (no fight): ' + ' signifies lethal interactions among the termites but with no consistent trend toward a victor. 


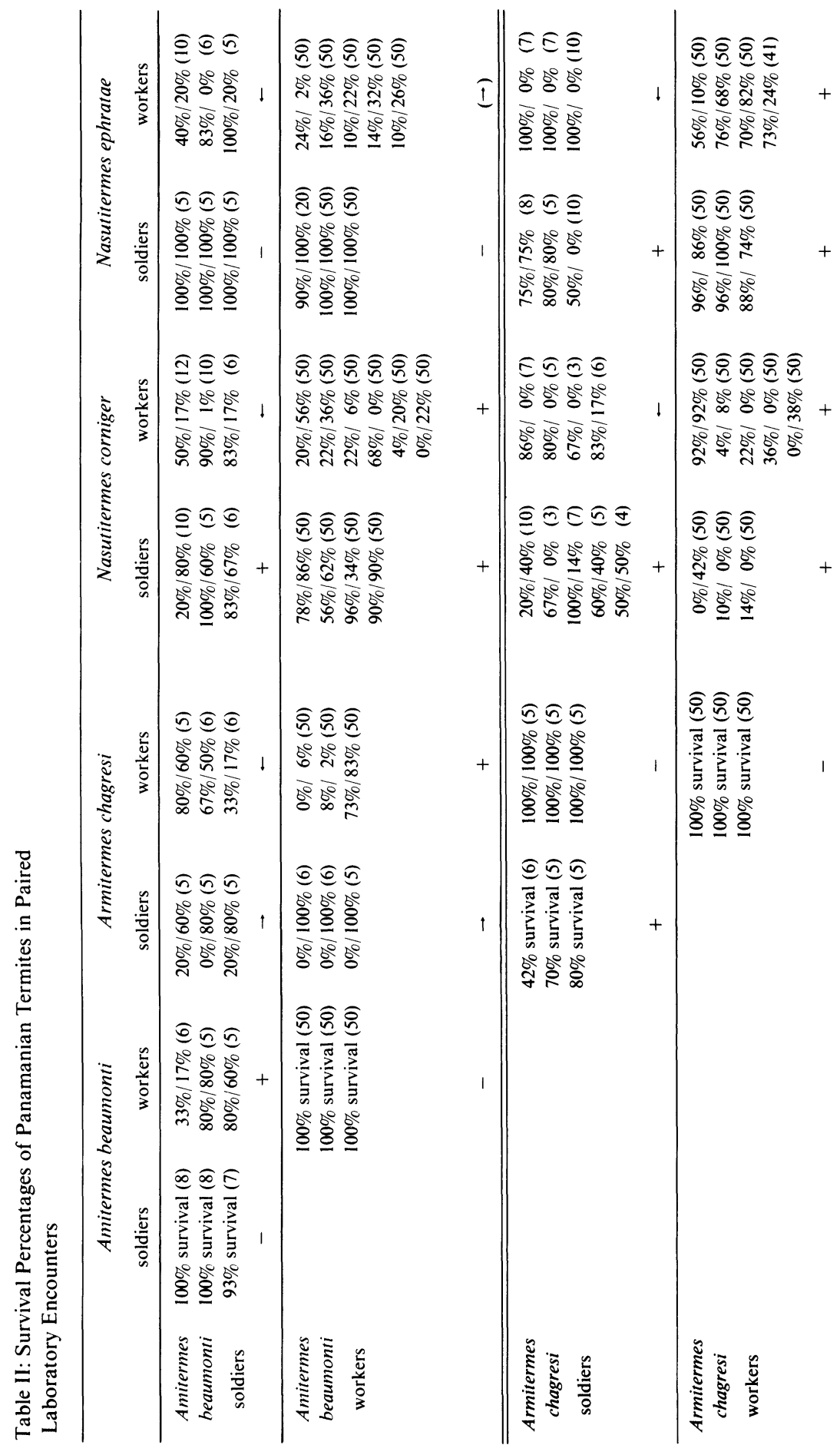




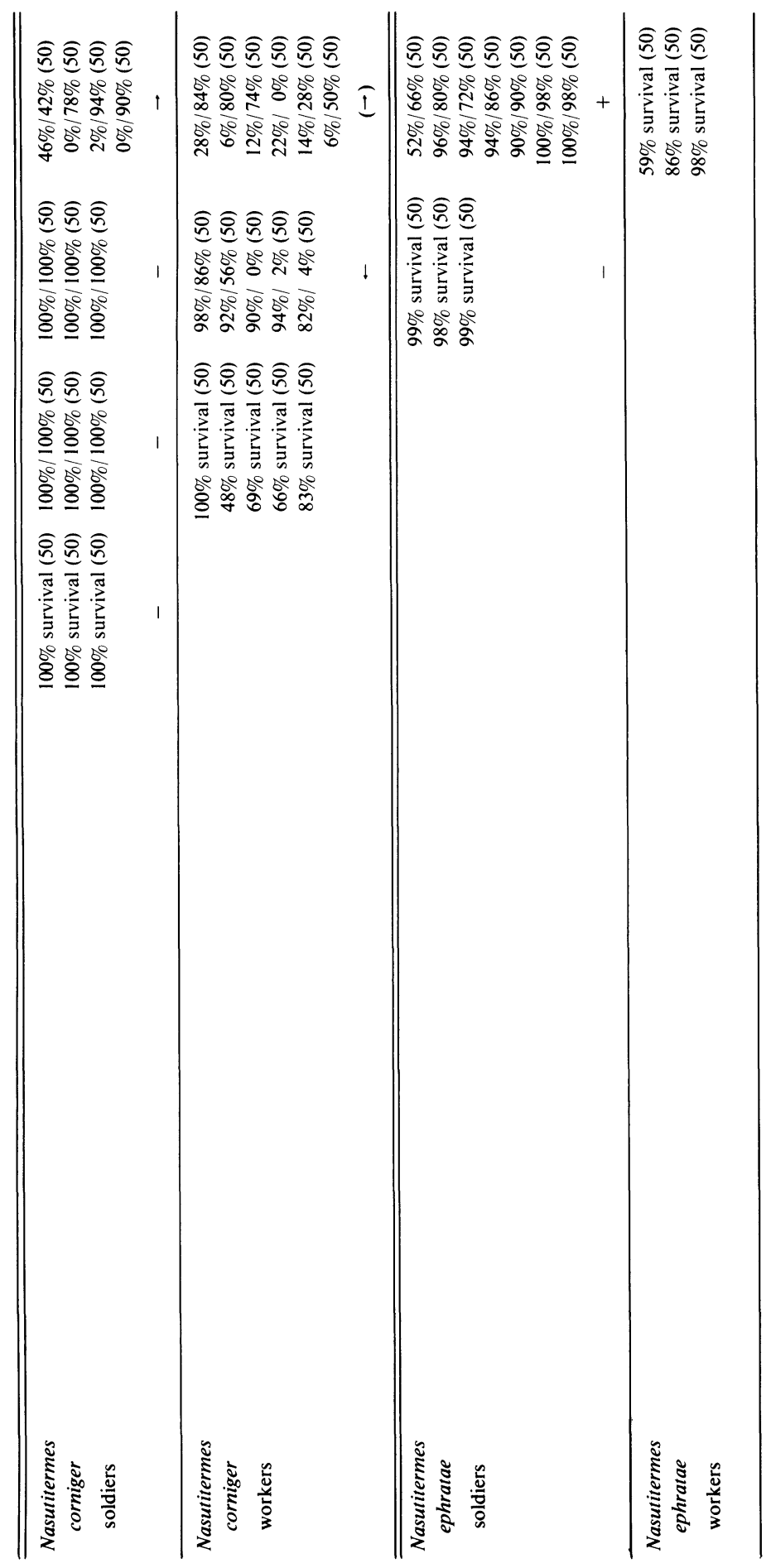


Table III: Analysis of Injuries for 7 Paired Worker-Worker Interactions

\begin{tabular}{|c|c|c|c|c|c|}
\hline & $\begin{array}{l}\text { Percentage } \\
\text { of } \\
\text { Individuals } \\
\text { with } \\
\text { Abdominal } \\
\text { Wounds }\end{array}$ & Antennal & Legs & Heads & $\begin{array}{c}\text { Mean Number } \\
\text { of } \\
\text { Non-Abdominal } \\
\text { Wounds Per } \\
\text { Individual }\end{array}$ \\
\hline $\begin{array}{l}\text { Armitermes chagresi ( } 10 \text { of } 12) \\
\text { vs }\end{array}$ & $100 \%$ & 5 & 6 & 1 & 1.20 \\
\hline Nasutitermes ephratae (16) & $87.5 \%$ & 7 & 6 & 2 & 0.94 \\
\hline $\begin{array}{l}\text { Armitermes chagresi ( } 20 \text { of } 21) \\
\text { vs }\end{array}$ & - & 3 & 13 & 3 & 1.00 \\
\hline Nasutitermes ephratae (43) & - & 41 & 61 & 0 & 2.37 \\
\hline $\begin{array}{l}\text { Nasutitermes ephratae (8) } \\
\text { vs }\end{array}$ & $87.5 \%$ & 2 & 6 & 1 & 1.12 \\
\hline Nasutitermes corniger (41) & $78.0 \%$ & 30 & 125 & 1 & 3.83 \\
\hline $\begin{array}{l}\text { Nasutitermes ephratae (12) } \\
\text { vs }\end{array}$ & $100 \%$ & 3 & 13 & 0 & 1.25 \\
\hline Nasutitermes corniger (43) & $90.7 \%$ & 27 & 169 & 0 & 4.56 \\
\hline $\begin{array}{l}\text { Amitermes beaumonti (32 of } 38) \\
\text { vs }\end{array}$ & $65.6 \%$ & 36 & 32 & 20 & 2.75 \\
\hline Nasutitermes ephratae (46) & $82.6 \%$ & 39 & 46 & 0 & 1.85 \\
\hline $\begin{array}{l}\text { Nasutitermes corniger (19) } \\
\text { vs }\end{array}$ & $73.7 \%$ & 12 & 25 & 1 & 2.05 \\
\hline Amitermes beaumonti (38) & $50.0 \%$ & 24 & 35 & 19 & 2.05 \\
\hline $\begin{array}{l}\text { Nasutitermes corniger (37) } \\
\text { vs }\end{array}$ & $67.6 \%$ & 47 & 113 & 0 & 4.32 \\
\hline Amiterme (38) & $50.0 \%$ & 24 & 35 & 19 & 2.05 \\
\hline $\begin{array}{l}\text { Nasutitermes corniger (37) } \\
\text { vs }\end{array}$ & $67.6 \%$ & 47 & 113 & 0 & 4.32 \\
\hline Amitermes beaumonti (39) & $35.9 \%$ & 28 & 53 & 16 & 2.51 \\
\hline
\end{tabular}

Numbers in parentheses following species names are the number of individuals examined (killed). The colony with the fewest deaths is listed first for each interaction. Descriptions of the injury categories and criteria are described in text Section B under Results. 
Damage to each antennae and leg was scored separately, and a pierced or decapitated head was scored as one head injury, even if multiple punctures were present. Thus for 10 dead termites, a maximum of 20 antennal, $60 \mathrm{leg}$, and 10 head injuries were possible. That number of cumulative injuries divided by the total number of termites examined yielded the mean number of non-abdominal injuries per individual. This index gives some indication of the intensity of attack.

The frequency of antennal, leg, and head injuries shows that $\mathrm{Ami}$ termes beaumonti heads appear relatively vulnerable (at least when faced by Nasutitermes), and that $N$. corniger was prone to numerous leg injuries.

\section{DISCUSSION}

Worker termites of some species join in aggressive encounters with members of other colonies and are often adept fighters, particularly against other workers. Intensity and outcome of agonistic encounters is variable depending on the species, colonies, and castes involved. Soldiers also participate in termite-termite conflicts. This study suggests that mandibulate soldiers are more effective one-on-one inter-specific antagonists than are Nasutitermes soldiers, although nasute soldiers are generally present in higher numbers per colony and may be more effective in groups.

Research on termite-termite encounters has not been extensive, but is of interest because the recognized defensive caste, the soldiers, are not the sole participants, and may not join in such interactions at all. After viewing the attack of an introduced Termes worker by nymphs and larvae in a Calotermes colony, Grassi and Sandias write in their 1896-1897 account (p. 283), “... similar observations have been made several times, and show... that the soldiers purposefully reserve themselves for more important foes." Pickens (1934) noted that workers of established Reticulitermes hesperus colonies will attack and kill founding pairs and incipient colonies which settle nearby.

Andrews (1911) did an extensive series of intra-specific interaction experiments with Nasutitermes rippertii. Nearly all staged encounters resulted in immediate conflict involving both soldiers and workers, although occasionally two colonies were completely docile towards each other. Andrews also came to the conclusion 
that "different communities (colonies) have different grades of hostility" (p. 218). Studying Coptotermes acinaciformis, Howick and Creffield (1980) similarly report inter-colony variance in degree of aggression.

The mechanism by which termites recognize non-colony members, and the associated stimuli for aggressive response, are not understood. Termites of some species quickly discriminate between colony-mates and foreigners; other species seem oblivious to "aliens". Certain treatments have been shown to interfere with recognition or aggressive behaviors: water washes (Andrews 1911), chilling termites to immobilization (Dropkin 1946; Howick \& Creffield 1980), and laboratory rearing (Nel 1968). Unpigmented immatures of some species appear immune from attack (Andrews 1911, Sands $\&$ Lamb 1975). Dudley and Beaumont (1889a) postulated that colony members bear like "odors", and that they can thereby differentiate colony-mates from foreigners. This idea of what is now termed colony-specific recognition pheromones is still viable (reviewed by Stuart 1970), perhaps involving cuticular hydrocarbons as recognition cues (Howard et al. 1978, Blomquist et al. 1979). The degree of intraspecific pheromone variation, the environmental components of response, and the mode of aggressive stimulus remain unknown.

Workers may be particularly useful as a capable, defensive unit in termite-termite encounters because they are the numerically dominant caste and although they are accompanied by soldiers on foraging forays, they are vulnerable to predation and competition while foraging. Termite mounds and arboreal nests have few exposed openings, and any which exist are guarded, usually by soldiers. In contrast, worker foragers cannot rely on nest protection, and their armada of soldier escorts may be insufficient to stay competitors. Mandibulate soldiers are normally in low proportion relative to workers (Haverty 1977). The ratio of termite soldiers to workers in Nasutitermes is relatively high (Haverty 1977), but the soldiers have vestigal mandibles and their chemical sprays are apparently not a complete defense against other termites. Soldiers may be especially proficient at repelling ant and vertebrate attacks (although workers may assist, eg. Eisner et al. 1976), while worker castes are adept at joining with soldiers to defend resources against other termites. 


\section{ACKNOWLEDGEMENTS}

I thank C. Justine Allen and Kent H. Redford for special assistance, and the Organization for Tropical Studies and the Smithsonian Tropical Research Institute for logistical support. Kenneth P. Sebens, James F. A. Traniello, and Edward O. Wilson read earlier versions of this paper. This research was funded by NSF dissertation improvement grant DEB-80-16415 and a predoctoral fellowship from the American Association of University Women.

\section{REFERENCES}

ANDrews, E. A.

1911. Observations on termites in Jamaica. J. Anim. Behav. 1: 193-228.

Blomquist, G. J.; R. W. Howard and C. A. MCDaniel.

1979. Structures of the cuticular hydrocarbons of the termite Zootermospis angusticollis (Hagen). Insect Biochem. 9: 365-370.

Clément, J.

1978. L'agression interspécifique et interspécific des espèces française du genre Reticulitermes (Isoptère). C. R. Acad. Sc. Paris. 286: 351-354.

DROPKIN, V. H.

1946. The use of mixed colonies of termites in the study of host-symbiont relations. J. Parasit. 32: 247-251.

Dudley, P. H. AND J. Beaumont.

1889a. Observations on the termites, or white-ants of the Isthmus of Panama. Trans. N. Y. Acad. Sci. 8: 85-114.

1889b. The termites or so-called "white-ants" of the Isthmus of Panama. J. N. Y. Microscop. Soc. 5: 59-70 and 111-112.

Eisner, T.; I. KRiston AND D. J. Aneshansley.

1976. Defensive behavior of a termite (Nasutitermes exitiosus). Behav. Ecol. and Sociobiol. 1: 83-125.

Grassi, B. AND A. Sandias.

1896-1897. The constitution and development of the society of termites: Observations on their habits: with appendices on the parasitic protozoa of Termitidae, and on the Embiidae. Quart. J. Microsc. Sci. 39: 245-322; 40: $1-82$.

HAVERTY, M. I.

1977. The proportion of soldiers in termite colonies: a list and a bibliography (Isoptera). Sociobiology 2(3): 119-216.

Howard, R. W.; C. A. MCDaniel and G. L. Blomquist.

1978. Cuticular hydrocarbons of the eastern subterranean termite, Reticulitermes flavipes (Kollar) (Isoptera: Rhinotermitidae). J. Chem. Ecol. 4(2): 233-245. 
Howick, C. D. AND J. W. CReffield.

1980. Intraspecific antagonism in Coptotermes acinaciformis (Froggatt) (Isoptera: Rhinotermitidae). Bull. of Ent. Res. 70: 17-23.

NeL, J. J. C.

1968. Aggressive behaviour of the harvester termites Hodotermes mossambicus (Hagen) and Trinervitermes trinervoides (Sjostedt). Ins. Soc. 15(2): 145-156.

Pickens, A. L.

1934. The biology and economic significance of the western subterranean termite Reticulitermes hesperus. In: Termites and Termite Control (C. A. Kofoid, ed.) Ch. 14 pp. 157-183. Univ. of Calif. Press, Berkeley.

Prestwich, G. D.

1979. Chemical defense by termite soldiers. J. of Chem. Ecol. 5(3): 459-480.

Sands, W. A. and R. W. Lamb.

1975. The systematic position of Kaudernitermes gen. n. (Isoptera: Termitidae, Nasutitermitinae) and its relevance to host relationships of termitophilous staphylinid beetles. J. of Ent. Series B Vol. 44 Pt. 2, pp. 189-200.

STUART, A. M.

1969. Social behavior and communciation. In: Biology of Termites (K. Krishna and F. M. Weesner, eds.). Vol. I pp. 193-232. Academic Press, N. Y.

1970. The role of chemicals in termite communication. In: Advances in Chemoreception Vol. I: Communication by Chemical Signals (J. W. Johnson, Jr.; D. G. Moulton \& A. Turk, eds.). pp. 79-106. AppletonCentury-Crofts, N. Y.

THORNE, B. L.

1980. Differences in nest architecture between the Neotropical arboreal termites Nasutitermes corniger and Nasutitermes ephratae (Isoptera: Termitidae). Psyche 87: 235-243.

THORNE, B. L. AND C. NOIROT.

1982. Ergatoid reproductives in Nasutitermes corniger (Motschulsky): Isoptera, Termitidae. International J. of Insect Morph. and Embryol., in press.

Traniello, J. F. A.

1981. Enemy deterrence in the recruitment strategy of a termite: Soldierorganized foraging in Nasutitermes costalis. Proc. Nat. Acad. Sci. 78(3): 1976-1979. 

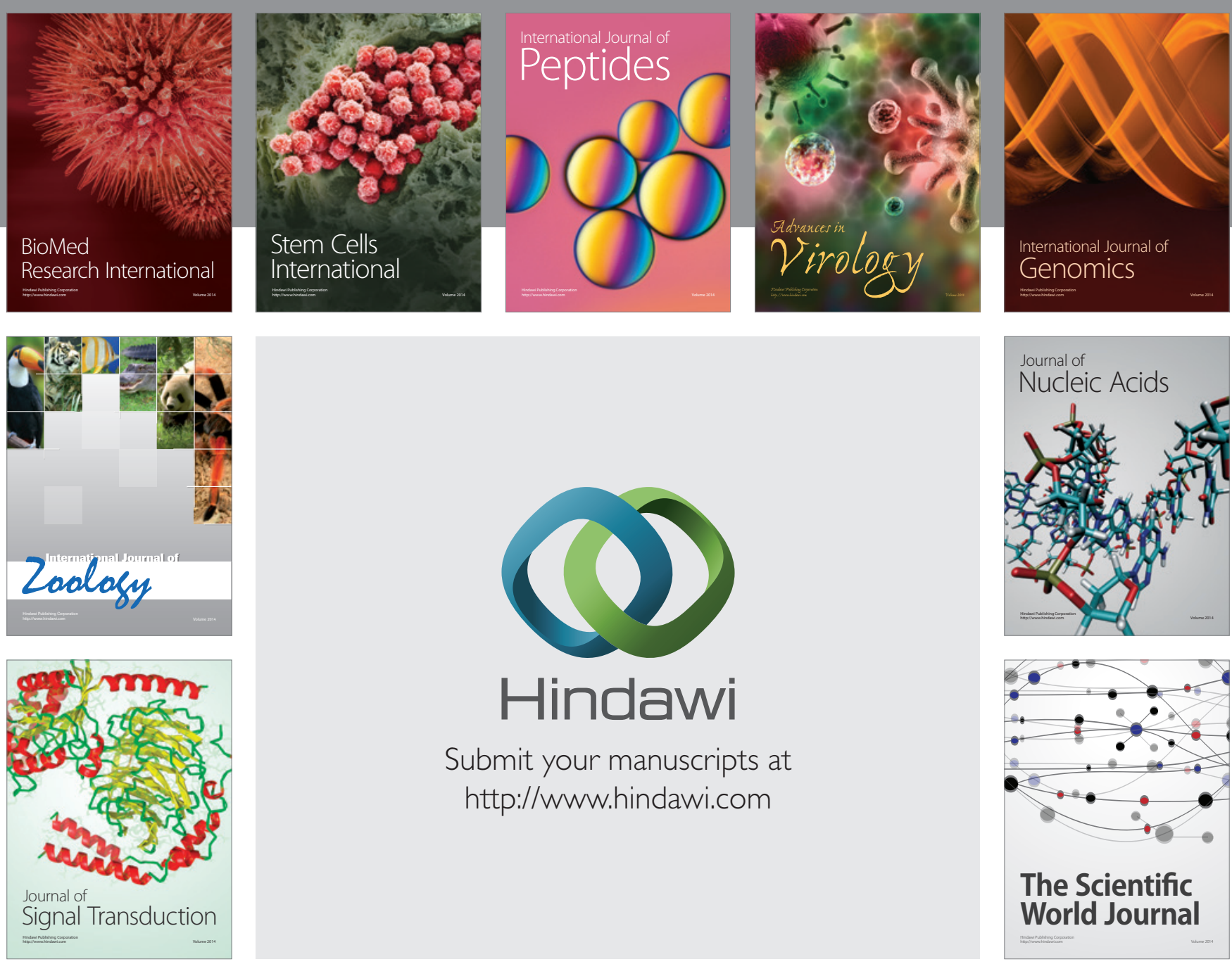

Submit your manuscripts at

http://www.hindawi.com
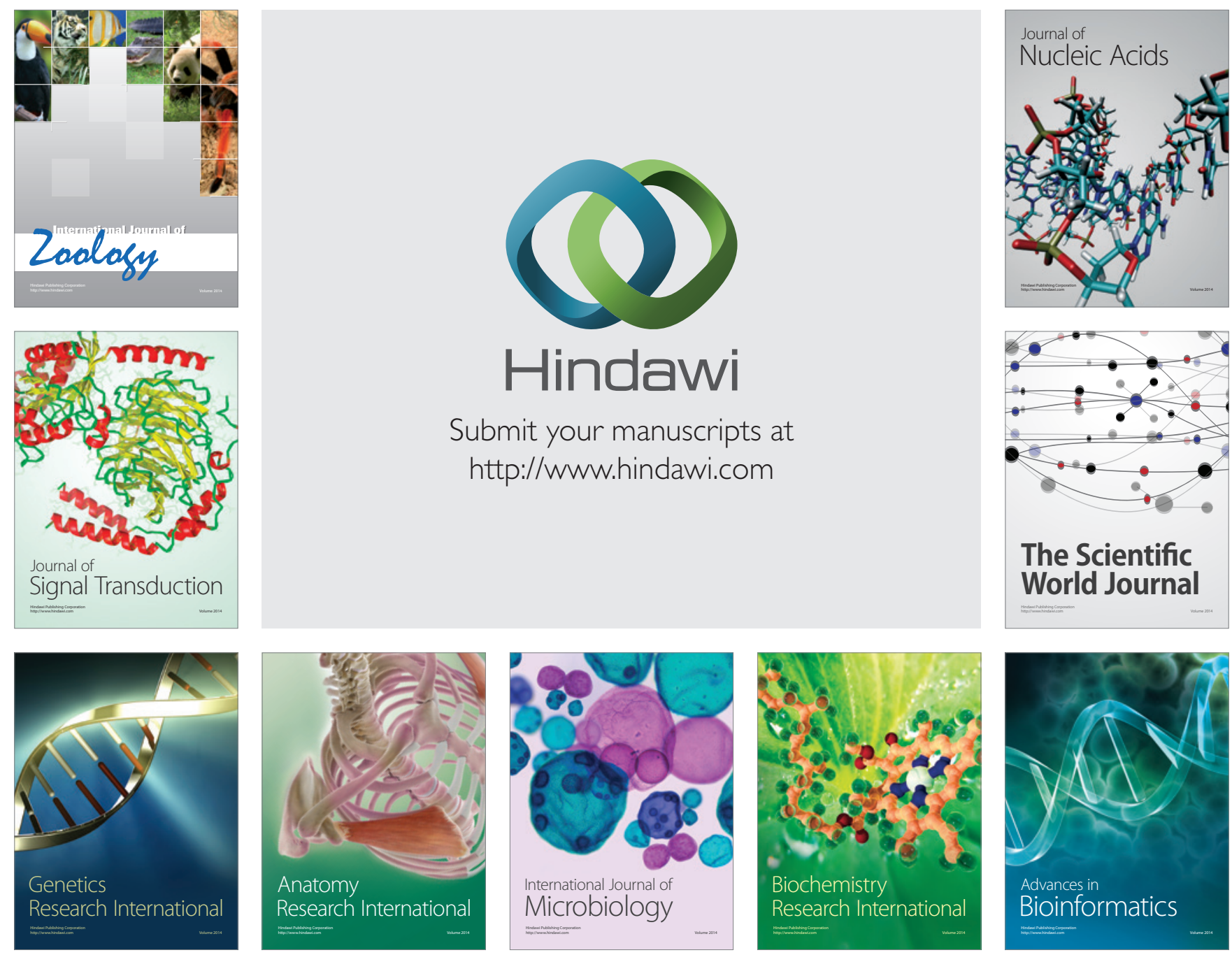

The Scientific World Journal
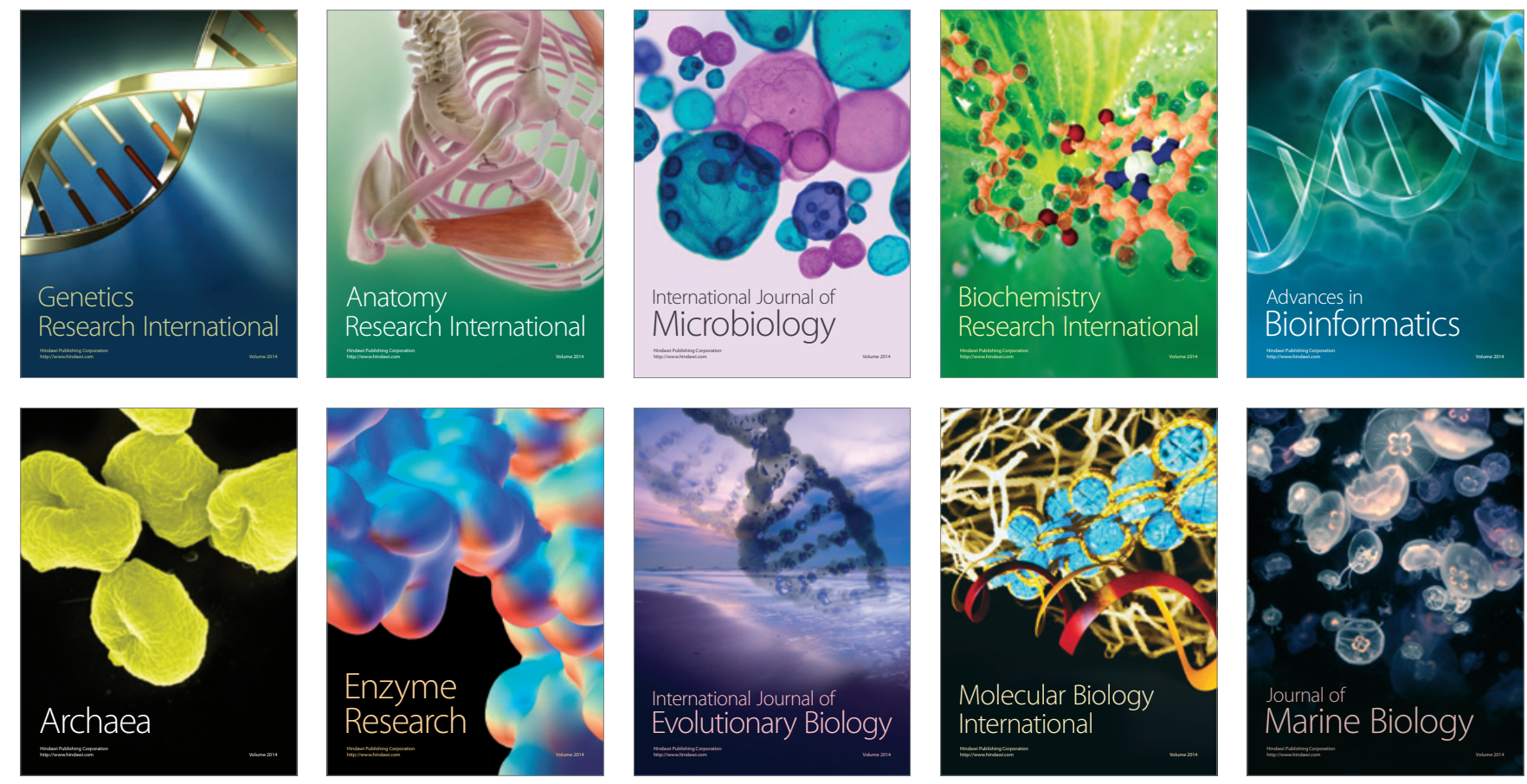